\title{
THE IMMERSION CYCLE: UNDERSTANDING IMMERSIVE EXPERIENCES THROUGH A CYCLICAL MODEL
}

\author{
Lucho Lingan, Cesar (1,2); \\ Li, Meng (2,3); \\ Vermeeren, Arnold P.O.S. (2) \\ 1: Pontificia Universidad Católica del Perú; \\ 2: Delft University of Technology; \\ 3: Xi'an Jiaotong University
}

\begin{abstract}
The present work introduces a cyclical model which showcases the process of immersion during Immersive Technological Experiences (ITEs) such as Virtual Reality, Augmented Reality and Mixed Reality. This model is based on the identified concepts around immersion and immersive environments across 30 years. The concepts' similarities were used to organize them on a cyclical model by acknowledging the user's presence at the beginning and end of immersive experiences. The proposed model's value relies on its cyclical approach based on a user-centred perspective and having a general overview of the immersion process. The Immersive cycle can serve as a mapping tool for developers and researchers, thanks to the inclusion of guidelines that complements the model. Both of these were used in three different examples of ITEs. Furthermore, the cyclical model could be used as a tool for ideation and conceptualization during the early stages of developing immersive experiences. Nevertheless, it is recognized that this is the first step in developing this model; therefore, it still needs to be validated and improved based on tests with developers, designers and researchers in the field.
\end{abstract}

Keywords: User centred design, Design methods, Virtual reality

\author{
Contact: \\ Lucho Lingan, Cesar Ruben \\ Pontificia Universidad Catolica del Peru \\ Art and Design \\ Peru \\ cesar.lucho@pucp.edu.pe
}




\section{INTRODUCTION}

Our society is evolving in motion, and the advancing of technologies fuels this trend. These societaltechnological challenges reshape the processes of designing and developing products and services. Among these technologies, immersive technologies form one of the most prominent illustrations. Virtual Reality, Augmented Reality (AR), and Mixed Reality (MR) are well-known examples of immersive technologies, which "presents a vivid virtual environment while shutting out physical reality" (Cummings and Bailensen, 2016). Since its first manifestation, the idea of using software and hardware to stimulate, enhance and complement real-life environments have been widely studied and used by different researchers and practitioners across different fields. From the understanding of technology's role in the diverse types of immersive experiences in our contemporary life to the development of different ways of understanding immersive experiences (Kim et al., 2018; Pan et al., 2006). The combination of immersive technologies with the activities among different fields creates what is known as immersive experiences.

Presence, the core of immersive experiences, is defined as "the subjective experience of being in one place or environment, even when one is physically situated in another" (Witmer and Singer, 1998). On the other hand, the definition of "immersion" is either a synonym or a subcomponent of presence (McGloin, Farrar and Krcmar, 2013; Witmer and Singer, 1998). Slater and Wilbur (1997) proposed a distinct difference between "presence" and "immersion": presence describes the psychological functions of humans while immersion depicts the quality of technological systems (Slater and Wilbur, 1997). Although these research, theories and models were focused mainly on technological aspects of immersive experiences, an approach is missing: A user-centred perspective for understanding the general processes users undergo when they are part of virtual environments. Hence, the present work focuses on collecting immersive experience related terminologies proposed by different researchers and organizing them into a model that addresses the user as a core during the immersion process. Our model identifies the different concepts that different researchers (across time) have addressed as part of this immersive process, which is this paper's aim. Furthermore, the possibility of using this model as a tool for researchers and developers is introduced with a guideline checklist for sparking conversations across the stakeholders who are in charge of developing immersive experience with technologies.

In this paper, an overview of similarities and differences of various immersive technologies and their contribution to immersive experiences is introduced in section 2. Next, immersion as a phenomenon will be presented, and how it is being understood in the entertainment industry and educational training field are presented in section 3. Following this, in section 4, the identified concepts will be organized into a linear process and transformed into a cycle by the user's presence. In section 5, a comparison between the proposed model with existing models to highlight its differences will be presented. In addition, a guideline checklist that complements the cyclical model as a mapping tool will be introduced. The 6th section explains how developers and designers could use the cyclical model alongside the guideline checklist to understand immersive experiences from the cyclical perspective. Finally, the last section presents an overview of future research for further developing and validation.

\section{IMMERSIVE TECHNOLOGICAL EXPERIENCES - SIMILARITIES AND DIFFERENCES ACROSS TIME}

Immersive technological experiences (ITEs) reflect the goal of triggering the feeling of immersion during an experience. Across time, different researchers tried classifying these type of experiences based on the technology use: By how it was displayed or the type of peripheral devices it required (Psotka, 1995), to how these technologies interact with its users and their surroundings (Milgram et al., 1995; Azuma, 1997; Bowman and McMahan, 2007; Catalano, 2011).

In recent times, the categorization introduces three types of ITEs: Virtual Reality (VR), Augmented Reality (AR) and Mixed Reality (MR). Virtual reality takes advantage of generating virtual environments around its users, typically by asking its user to use a head-mounted display device (HDM). The software and hardware's processing power affect the realism and the sensorial experience delivered through this ITE type (Psotka, 1995). Augmented reality combines real-life environments with computer-generated perceptual elements, creating an "enhanced real-life environment" (Azuma, 1997). To achieve this, it is necessary to possess a device with the necessary technical features to display the generated virtual elements to the user. Currently, the most common devices for this are 
smartphones and tablets. By experimenting with the different types of perceptual and sensorial cues used to enhance AR's existing interaction, the concept of MR arises (Milgram et al. 1995). The relationships between the computer-generated elements and real-life elements from the environments are intertwined and symbiotic. For example, while a real-life element can provide the idea of an object's weight or texture, the computer-generated elements can visually overlap the real-life environment to complete the object's features in terms of colours and final shape. This immersive experience involves a more in-depth understanding of the relationships between the real-life elements and the computer-generated elements. Additionally, MR requires a similar device as AR. Furthermore, even though the technology and the type of experience have been changing across time, the core goal has not: to allow ITE users to feel immersed during the experience. This leads to the following question: How does immersion occur?

\section{UNDERSTANDING IMMERSION AS A PHENOMENON}

Immersion is a phenomenon that has been studied for the last 30 years. During this time, different theories about how immersion occurs have been proposed. Two of the most prominent fields in which these are used today were analysed: Entertainment and educational training. The concepts that are found and are similar in this field will be presented.

In the entertainment field, video game experiences are the most representative form of ITEs. Thanks to virtual environments' immersive capabilities, the overall experience is enhanced (Nacke and Lindley, 2008; Catalano, 2011; Althoff et al., 2016; Paavilainen et al., 2017; Tran Duy, 2017). In educational training, operational training has benefited from immersive experiences. In both cases, immersive realities take advantages of sensorial stimuli during the simulated experience, which affect user's objective-focus reasoning but also on their emotions and moods (Azuma, 1997; Ahmed et al., 2018; Halabi and Halwani, 2018; Huber et al., 2018; Li et al., 2020).

This situation relates to what different authors introduce as the "being there" effect, based on the described feeling of being part of something happening around the ITEs' users. A starting point to achieve this relies on senses (Psotka, 1995; Slater and Wilbur, 1997; Bowman, McMahan, 2008; Ermi and Mäyrä, 2005; Dangxiao et al., 2019). Based on the idea of senses, different authors establish the ideas of sensorial stimuli, sensorial immersion and sensorial fidelity. Sensorial stimuli comprise the senses' effects during an ITE over its users (Psotka, 1995; Bowman and McMahan, 2007). Sensorial immersion combines the sensorial stimuli and combines them with the action, interactions and dynamics between the ITE's user and the simulated (or partially simulated) environments Ermi and Mäyrä, 2005; Dangxiao et al., 2019). Finally, sensorial fidelity is the similarity between the sensorial stimuli from real-world environments or simulated environments users experience in the present with past real-world/ simulated environments (Bowman and McMahan, 2008).

The stimuli, interactions, actions, and dynamics during the experience are collected in people's memories. The sensorial stimuli are connected to short-term memory (Carlson, 2010, 7th edition), while the actions, interactions and dynamics are connected to the cognitive memory (Csikszentmihalyi, 1990). With these, ITEs' users can recall and link specific actions, dynamics or interactions they performed during an ITE or sensorial stimuli with past experiences from real-world scenarios or other simulated environments. This recalling and linking lead the user to feel aware of their presence during the ITE, similar to real-life environments (Slater, 2003). Moreover, as Slater and Wilbur stated, the idea of presence represents the subjective and psychological consequence from sensorial immersion and stimuli (1997). In contrast, immersion represents what could happen in a system where the illusion of reality through sensorial stimuli can be achieved, becoming objective and quantifiable (Slater and Wilbur, 1997). This idea means that ITE's users require to be aware of their presence by performing different actions, dynamics, and interactions alongside sensorial stimuli during the experience to create the idea of immersion.

The actions, dynamics and interactions define what is known as the level of involvement, which affects the user's interest through the experience. This interest is also affected by the engagement factor, defined by O'Brien and Toms, as "a category of user experience characterised by attributes of challenge, positive affect, endurability, aesthetic and sensory appeal, attention, feedback, variety/novelty, interactivity, and perceived user control" (2008). The engagement of an experience is strongly connected to the "Flow Theory" (Csikszentmihalyi, 1990), balancing the perceived level of challenge and the skills of the person (Buchanan and Csikszentmihalyi, 1991) in reaching the "flow state", which is "a holistic sensation that people feel when they act with total involvement" (2000). The Challenge factor during an experience is 
also explored and presented by Ermi and Mäyrä and O'Brien and Toms (2005; 2008). According to Ermi and Mäyrä, it is possible to achieve immersion by combining the environment with involvement and engagement through challenge-based activities, as it is common in video games (2005). The relation between engagement, "flow", and immersion is also addressed by Shin (2017).

In turn, the engagement and involvement factors are linked to imagination and imaginative immersion (Ermi and Mäyrä, 2005; Dangxiao et al., 2019). Through the matrix of experiences proposed by Pine and Gilmore, the relation between imaginative immersion, engagement, and involvement can be understood (1999). In this matrix, the participation and connection variables can determine how people will face an experience in terms of their actions (active or passive participation) and their presence (immersive or absorptive connection). The possible resultant combinations of these, also known as "natures of the experience" (e.g., escapist, esthetic), are not static but dynamic ones, depending on how these variables change across time.

As mentioned at the beginning of this chapter, the various concepts and theories relate to each other. To organise these different concepts, these were clustered and compared. In Figure 1, the different concepts addressed across each author are presented.

\begin{tabular}{|c|c|c|c|c|c|c|c|c|c|c|c|c|}
\hline $\begin{array}{r}\text { Bowman and } \\
\text { McMahan (2007) }\end{array}$ & $x$ & $\mathrm{x}$ & & $x$ & $x$ & & & & & & & \\
\hline \begin{tabular}{|} 
Dangxiao et al. \\
(2019)
\end{tabular} & $\mathrm{x}$ & & $x$ & & & & & & & & $\mathrm{x}$ & \\
\hline $\begin{array}{r}\text { Ermi and } \\
\text { Mäyrä (2005) }\end{array}$ & $x$ & & $\mathrm{x}$ & & & $x$ & & & $x$ & & & \\
\hline $\begin{array}{l}\text { O'Brien and } \\
\text { Toms (2008) }\end{array}$ & & & & $x$ & & $\mathrm{x}$ & & & & & $\mathrm{x}$ & $x$ \\
\hline $\begin{array}{r}\text { Pine and } \\
\text { Gillmore (1999) }\end{array}$ & & & & & & & $x$ & $\mathrm{x}$ & $x$ & & & \\
\hline Psotka (1995) & $\mathrm{x}$ & & & $\mathrm{x}$ & $x$ & & & & & & & \\
\hline Shin (2017) & $\mathrm{x}$ & & & & $\mathrm{x}$ & & & & & $\mathrm{x}$ & & $x$ \\
\hline $\begin{array}{r}\text { Slater and } \\
\text { Wilbur (1997) }\end{array}$ & $x$ & & & & $x$ & & & $\mathrm{x}$ & & $\mathrm{x}$ & & \\
\hline
\end{tabular}

Figure 1. Referred concepts by different authors

\section{ARRANGING THE CONCEPTS: THE IMMERSIVE CYCLE (IC)}

These different concepts can be aligned into a single process in understanding how immersion is reached and what occurs with the user during it. Based on the sensorial stimuli and the level of involvement (interactions, actions and dynamics), it is possible to identify the nature of experience based on the participation and connection variables. The similarity of the user's previous experiences will confront the nature of the ITE (fidelity). Simultaneously, the imaginative immersion complements the ITE and the memory of past experiences. The ITE's fidelity with the user's past experiences, the imaginative immersion and the ITE's nature combined will address the engagement factor during the experience. Thanks to the engagement factor during the ITE, people will obtain the feeling of presence. By taking advantage of the engagement characteristics, the experience's developers can establish situational challenges across the ITE to reach the idea of immersion (as occurs in video games; Ermi and Mäyrä, 2005), which, as stated in this paper, will trigger the "being there" effect on the user.

However, due to the changing nature of the experience combined with the different stimuli, actions and interactions users will be facing across the general ITE, the immersive process cannot be expressed as a single process. During the ITE users will be confronting specific moments that could be either new for them, related to a past experience or a specific fragment of a past experience. In that regard, once users achieve the "being there" effect, the experience will be transformed into new memories. These new memories will relate either to the user's sensorial type of memories or cognitive type of memories.

Imagination appears as a central element among the immersive process. This element can be perceived as a general concept; however, it performs a pivotal role in the model. Imagination helps users make sense of what they are experiencing during an ITE; it can enhance the originally proposed experience and transform it into a more in-depth experience. Also, imagination interacts with the information from 
the stimuli, the ITE's level of involvement in conjunction with users' past experiences, helping them to understand what is happening during the experience. Moreover, if the experience possesses a cohesive narrative or story, the user's imagination can be guided, making sense of what users are experiencing.

Because the user becomes the starting element on the model and the end of the process, it was necessary to start looking at the immersive process throughout a cyclical model. Based on the mentioned points, the visual model proposed and developed for this paper will be known as the Immersive Cycle (IC, shown in Figure 2).

Alongside the user, the concepts of the user's past experiences, sensorial memory, cognitive memory and imagination will also be present during the cycle (Step 1). ITE's sensorial experiences and its level of involvement (proposed by the ITE's developers) will shape the user experience (Step 2). These two elements are intertwined in the experience and will affect the user's imagination. With these elements, the ITE's nature of the experience can be defined by the developers and unconsciously (or consciously) assessed by ITE's users based on the connection and participation variables (Step 3). Furthermore, users will confront the nature of the experience with their past experiences (Step 4). The experience's nature precedes the engagement factor (Step 5). The engagement factor could be benefited from situational challenges in conjunction with a proposed narrative or story through the ITE. The combination of these elements will lead to the immersion (Step 6), followed by the idea of presence (Step 7). The influence of presence and the ITE's narrative or story will help the user in reaching the "being there" effect (Step 8). Once the "being there" effect is reached, the ITE will transition into new memories (sensorial and cognitive), returning to Step 1. It is important to mention that the nature of experience (Step 4), the engagement factor (Step 5), immersion (Step 6), presence (Step 7) and the "being there effect" (Step 8) are affected by the user's imagination and vice versa. This situation happens due to the narrative or the story that goes across the experience. ITE developers and designers must think of the narrative or story because it will guide the users across the ITE (Brooks, 2003, Ermi and Mäyrä, 2005). Complementary, the Immersive cycle elements do not appear only once during an ITE; in reality, it happens at different times and speeds as long as the user is still exposed to the ITE and how the narrative or story is proposed and unfolds..

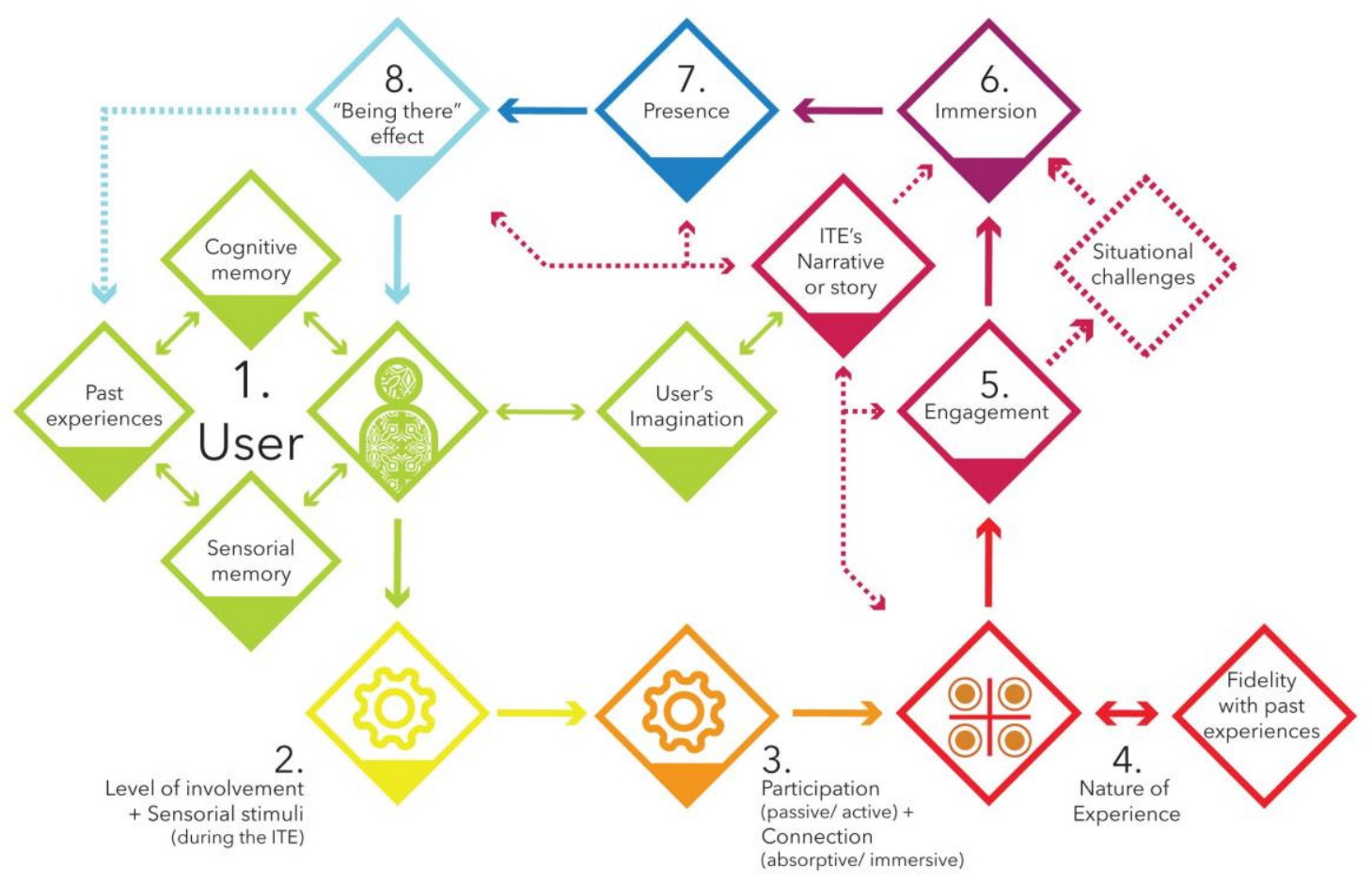

Figure 2. The Immersive cycle

\section{THE IMMERSIVE CYCLE AS A MODEL FOR IMMERSION FROM A USER- BASED PERSPECTIVE}

Currently, different models address immersion from different perspectives: Either from a specific type of experience as the SCI model of immersion (Ermi and Mäyrä, 2005); from a technical approach, like 
the Human-VE interaction loop (Bowman and McMahan, 2007); or focused on aspects of immersion that occurs during user experiences, like the model proposed by Shin (2017). Although the Immersive cycle shares concepts with these models, it distinguishes itself from these for different reasons.

The SCI-model tackles concepts that inspired the immersive cycle's creation, like past experiences, senses, and challenges. However, the SCI model focuses on gaming experiences (Ermi and Mäyrä, 2005). That is the main difference between it and the Immersive cycle: The IC focuses on general definitions for immersive experience transformed into new sensorial and cognitive memories. Nevertheless, this does not imply that the SCI cannot be used for other ITEs, but it would be necessary to have broader definitions for different applications.

The Human-VE interaction loop focuses on software and hardware concepts that are part of ITE (Bowman and McMahan, 2007). In contrast, the Immersive cycle focuses on what the user will experience through the immersion process.

Shin's model presents an interesting linear approach to immersion by dividing the concepts related to this phenomenon into two major parts: User experience and quality of experience (Shin, 2017). By having these interconnected concepts reaching engagement at the end of his model, the Immersive cycle can complement this model thanks to its cyclical approach. As we showcased, the immersive experience starts and ends with the user, showcasing the importance of having a cyclical approach.

Based on the previous comparisons, the Immersive cycle model relies on its general approach towards immersion from a user perspective while at the same time addressing the immersion process as a cyclical phenomenon, becoming an interesting opportunity for ITE developers in terms of organizing and proposing an experience. In that regard, a series of guidelines arranged as questions (per step) complements the IC (shown in Table 1). These guidelines have two focuses: The first one is to complement the visual cycle and be used as a mapping tool for immersive experiences based on the process users undergo while experiencing an ITE; and second, to work as a general guideline for earlystages in the development of an ITE. Unlike existing questionnaires like those developed by Witmer and Singer (1998), the Immersive cycle guidelines are oriented for starting a conversation rather than targeting concise or straightforward answers, giving the developers the necessary freedom for interpreting and defining an ITE's concept. The goal behind these guidelines is for starting a conversation between the developers and ITE designers in understanding the process from beginning to end rather than needing to answer as a typical questionnaire. Additionally, there are questions at the end of the method focused on general aspects or questions that are not necessarily related to one specific step. It is expected one would use the Immersive cycle as a flexible tool for ideation and conceptualization of an ITE rather than as a strict framework.

Table 1. Immersive cycle's guidelines

\begin{tabular}{|l|l|}
\hline Step & What we (as developers) can consider about the immersive process: \\
\hline 1. User & $\begin{array}{l}\text {-Which type of senses do we want to stimulate in the user? } \\
\text {-What do people remember from past experiences that can be used for the ITE? } \\
\text {-How will the user's imagination be triggered by the different elements and the } \\
\text { narrative across the experience? } \\
\text {-Who are the people that are going to become our ITE users? }\end{array}$ \\
\hline $\begin{array}{l}\text { 2. Level of } \\
\text { involvement }+ \\
\text { Sensorial stimuli }\end{array}$ & $\begin{array}{l}\text {-What do we want to introduce in terms of interactions, dynamics and actions } \\
\text { during the experience? } \\
\text {-What stimuli are we using alongside the interactions, dynamics and actions } \\
\text { during the experience? }\end{array}$ \\
\hline $\begin{array}{l}\text { 3. Participation }+ \\
\text { Connection }\end{array}$ & $\begin{array}{l}\text {-Does a user's actions affect the environment or other elements that are part of } \\
\text { the experience? } \\
\text {-Is the user is going to spectate as an outsider (its presence is just symbolic) or } \\
\text { as part of the experience? }\end{array}$ \\
\hline $\begin{array}{l}\text { 4. Nature of } \\
\text { experience }+ \\
\text { Fidelity with past } \\
\text { experiences }\end{array}$ & $\begin{array}{l}\text {-Based on the participation + connection answer. What is the nature of the } \\
\text { experience? } \\
\text {-Is this nature similar to experiences that the user has already lived? How } \\
\text { similar or different are they? }\end{array}$ \\
\hline $\begin{array}{l}\text { 5. Engagement } \\
\text {-How engaging is the narrative or story that we want to propose during the } \\
\text { experience? } \\
\text {-Do we need to challenge the user with something to keep him/her engaged? }\end{array}$ \\
\hline
\end{tabular}




\begin{tabular}{|l|l|}
\hline 6. Immersion & $\begin{array}{l}\text {-Are the previous elements cohesive between each other and do they make } \\
\text { sense within the proposed narrative or story? }\end{array}$ \\
\hline 7. Presence & $\begin{array}{l}\text {-Is the user reacting to what is experienced alongside the narrative? } \\
\text {-In which sense is this reaction: Cognitive, physical, or sensorial? }\end{array}$ \\
\hline $\begin{array}{l}\text { 8. "Being there" } \\
\text { effect }\end{array}$ & $\begin{array}{l}\text {-What are the elements that we expect the user to remember? Which specific } \\
\text { actions or sensorial stimuli in particular? } \\
\text {-Is the "Being there effect" achieved by the cohesion of the previous elements } \\
\text { that led to the immersion? }\end{array}$ \\
\hline $\begin{array}{l}\text { 9. Miscellaneous } \\
\text { (General) }\end{array}$ & $\begin{array}{l}\text {-What do we want to achieve with our ITE? } \\
\text {-Is there a necessity for a detailed narrative or story across the experience? }\end{array}$ \\
\hline
\end{tabular}

\section{CASE STUDIES: THE MODEL AS A MAPPING TOOL}

To understand the Ic's value at the moment of analyse ITE cases, the guidelines based had been utilised in three different existing ITEs. This decision aligns with the first possible use of the model and guidelines: to serve as a mapping tool on existing ITEs. The selected cases, shown in Figure 3, are the gravity gloves experience in Half-Life Alyx, a VR video game developed by Valve Corporation, displayed via high-end VR headset like Valve Index, HTC Vive, Oculus Rift, and MS Mixed Reality; a virtual prototype of the privacy protection seat in a future airplane cabin, developed by Delft University of Technology, displayed via HTC Vive; and the In-Car 6-DoF Mixed Reality for RearSeat and Co-Driver Entertainment by Haeling et al. in collaboration with Daimler AG (2018), displayed in Oculus Rift. In these three cases, users achieve the "being there" effect derived from various steps according to the guidelines (shown in Table 2). Furthermore, the following conditions were identified as keys to attaining an immersive experience: 1 . Multi-sensorial memory: at least three sensorial memories were concurrently activated, including iconic, echoic, and active or passive haptic. 2. "Ordinarity" of actions as involvement triggers: the virtual environment replicated the principles of actions from daily life, such as "pull-down" the virtual shelter with virtual hands. 3. Immersive connection: stereoscopic images from high-resolution VR headsets trigger the dominant sensation of vision, and isolate the distractions from local physical environments. 4. Active or passive engagement: either direct interaction (Alyx) to semi-automatic interaction (privacy seat) and simulated environmental stimuli, especially distractors (co-driver entertainment), could keep user attention throughout the experience. 5. Immersion: interactive narrative, full-scale prototype prototypes, or mixed stimuli could serve as the key triggers for the immersion. 6. Presence: physical, sensorial, cognitive reactions or the resonance between them were observed alongside the narrative.

In general, multi-sensorial sensation, ordinary interactions, and immersive connection from stereoscopy produced the "wow" effect for the first-time VR user, and the active or passive engagement retained their attention. The integration of perceptual sensation into the narrative and virtual embodiment of users needs further exploration to understand their compound effects in the immersive experience.

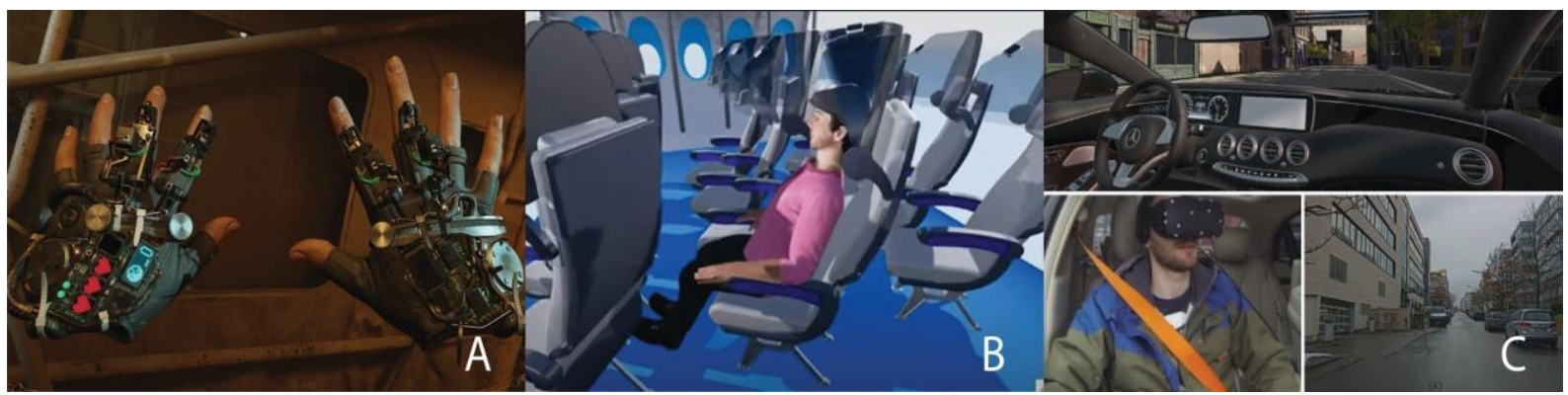

Figure 3. The three cases: A) the gravity gloves (source: theverge.com); B) the privacy protection aeroplane seat; $C$ ) the In-car 6-DoF mixed reality for rear-seat and co-driver entertainment (source: IEEExplore.org). 
Table 2. The cases through the guidelines

\begin{tabular}{|c|c|c|c|c|c|c|c|c|c|}
\hline 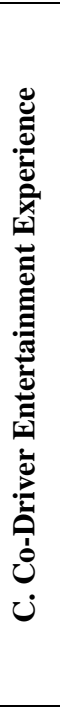 & 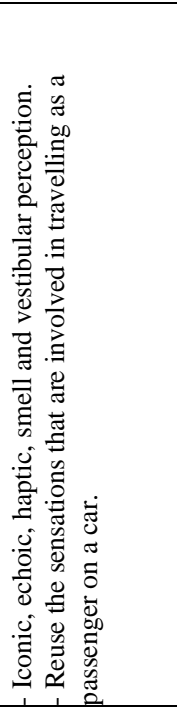 & 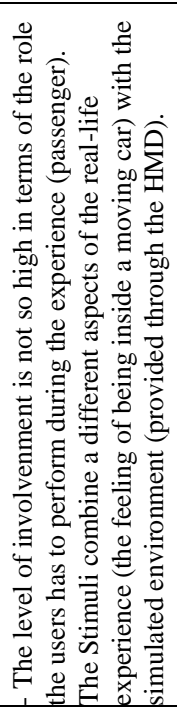 & 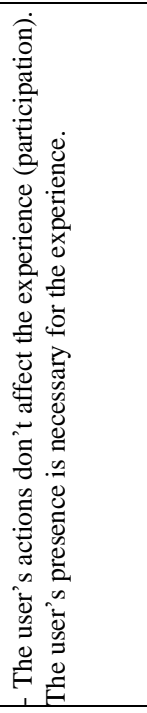 & 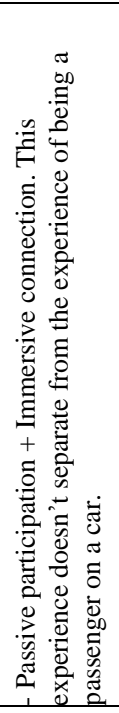 & 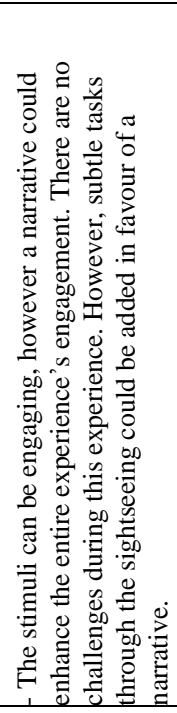 & 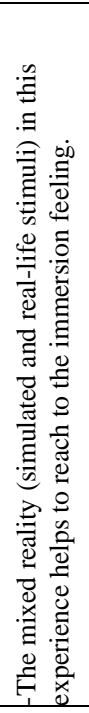 & 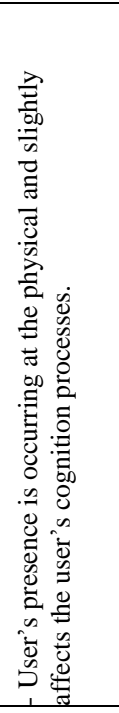 & 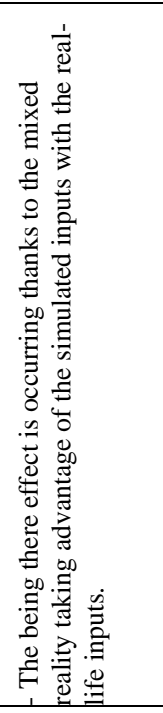 & 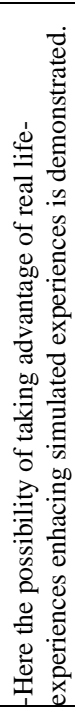 \\
\hline 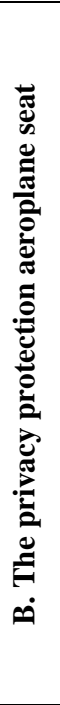 & 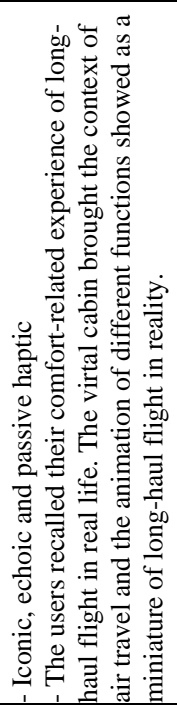 & 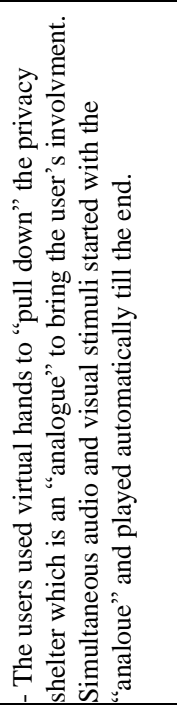 & 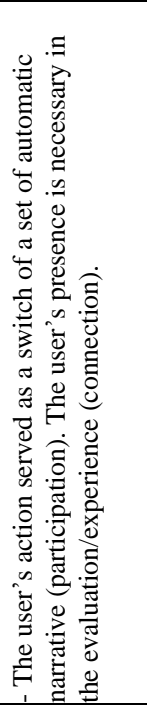 & 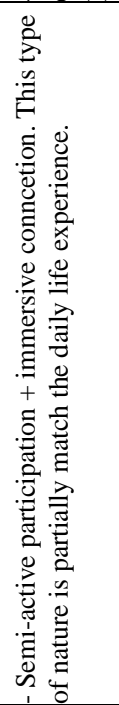 & 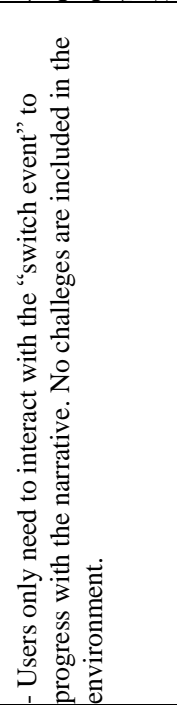 & 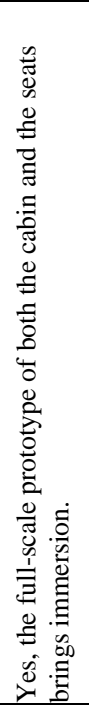 & 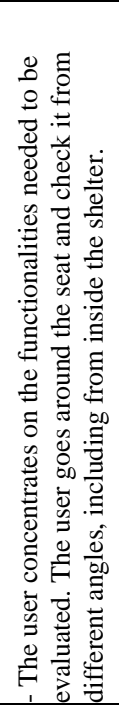 & 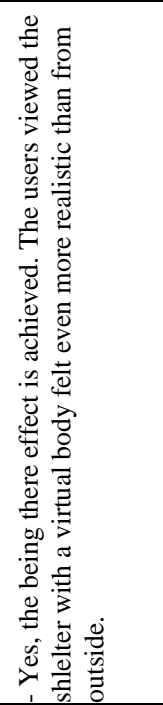 & 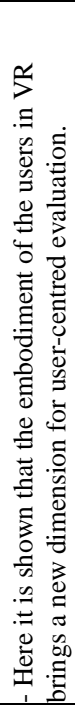 \\
\hline 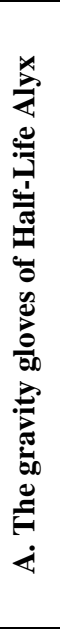 & 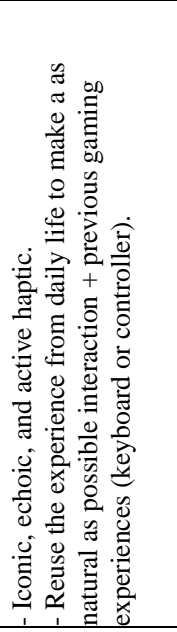 & 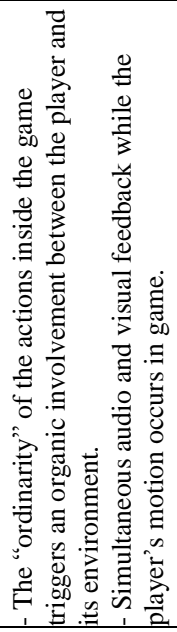 & 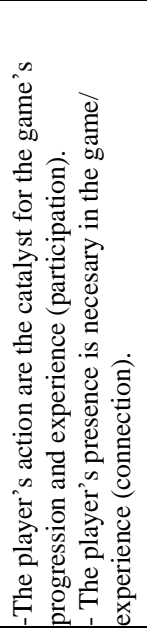 & 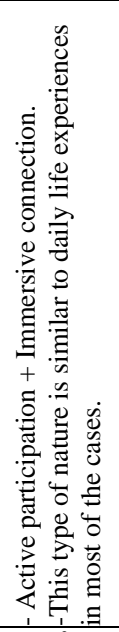 & 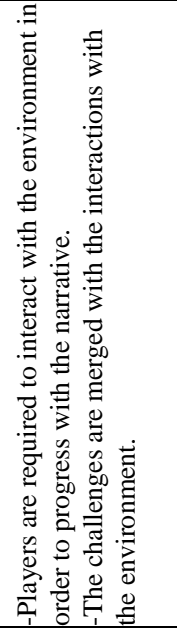 & 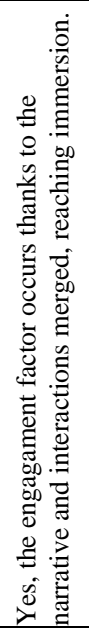 & 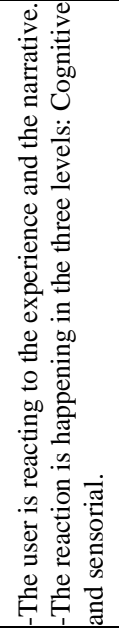 & 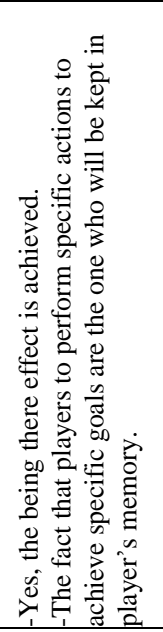 & 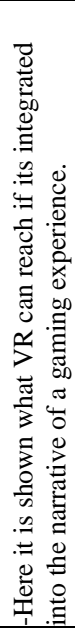 \\
\hline 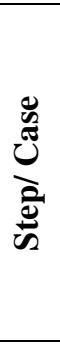 & 5 & 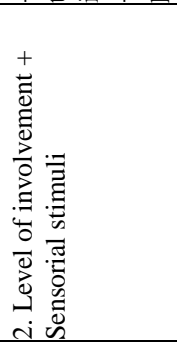 & $\begin{array}{l}\text { J̃ } \\
\text { ठ } \\
+ \\
\tilde{\Xi}\end{array}$ & 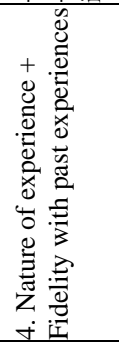 & in & $\overbrace{0}^{\prime \prime}$ & $\frac{3}{2}$ & 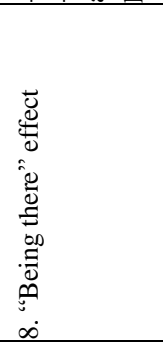 & 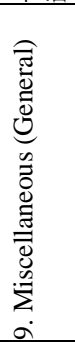 \\
\hline
\end{tabular}




\section{CONCLUSIONS AND FUTURE WORK}

The main advantage of the cyclical approach is the perspective. While traditional approaches relate to a developer's perspective, a cyclical approach introduces the user, focusing on developing a cyclical framework to understand immersion from a user's perspective.

With the introduction of a cyclical model to describe the process of immersion in Immersive technological experiences (ITEs) such as VR, AR and MR, the importance of the user across the process can be perceived. The user's role starts at the beginning of the immersion process, goes across the different steps that occur during an ITE, and finishes with the user again, collecting new memories based on the experience that he/she went through. Additionally, by recognising the steps involved in this cycle, VR, AR and MR researchers and developers have the opportunity for deep diving into the different characteristics their immersive experience proposal needs to have, as we demonstrated with the case studies. Furthermore, in that sense, developers and designers can use the IC as a mapping tool of the immersion process across different ITEs from a user perspective or as a conversation starter to ideate and conceptualise immersive experiences. The future applications of IC in ongoing products and services development need to focus on efficacy with developers and designers via various ITEs.

It is important to emphasise that this model does not necessarily introduce new theories about immersion but reorganising existing ones in a single model. Initially, this could be seen as not necessarily a novel approach. However, this approach addresses the user as the most important element during an immersive process, as it was shown during the comparing the IC with other existing models. Nevertheless, the model needs to be used on existing ITEs as study cases and needs to be used by developers in the early stages of designing or redesigning an ITE. In that sense, the proposed checklist that accompanies the visual framework (Figure 3) is a first version that will be iterated based on future testing sessions with ITEs developers, becoming the focus for future work.

\section{ACKNOWLEDGMENTS}

Meng Li gratefully acknowledge the grant from China Scholarship Council (CSC) (No. 201706280020) to support her doctoral study. The contents of this paper are solely the responsibility of the authors and do not necessarily represent the official views of CSC.

\section{REFERENCES}

Ahmed, S., Zhang, J., \& Demirel, O. (2018). Assessment of Types of Prototyping in Human-Centered Product Design. In International Conference on Digital Human Modeling and Applications in Health, Safety, Ergonomics and Risk Management (pp. 3-18). Springer, Cham. https://doi.org/10.1007/978-3-319-913971

Althoff, T., White, R. W., \& Horvitz, E. (2016). Influence of Pokémon Go on physical activity: study and implications. Journal of medical Internet research, 18(12), e315. https://doi.org/10.2196/jmir.6759

Azuma, R. T. (1997). A survey of augmented reality. Presence: Teleoperators \& Virtual Environments, 6(4), 355-385. https://doi.org/10.1162/pres.1997.6.4.355

Bowman, D. A., \& McMahan, R. P. (2007). Virtual reality: how much immersion is enough? Computer, 40(7), 36-43. https://doi,org/10.1109/MC.2007.257

Brooks, K. (2003). There is nothing virtual about immersion: Narrative immersion for VR and other interfaces. alumni. media. mit. edu/ brooks/storybiz/immersiveNotVirtual. pdf.

Buchanan, R., \& Csikszentmihalyi, M. (1991). Flow: The Psychology of Optimal Experience. Design Issues, $8(1), 80$.

Carlson, Neil R., 1942- (2010). Psychology: the science of behavior (7th ed). Allyn \& Bacon, Boston.

Catalano, G. (2011). Virtual Reality in Interactive Environments: A Comparative Analysis of Spatial Audio Engines. SAE Institute Oxford.

Csikszentmihalyi, M. (2000). Beyond boredom and anxiety. Jossey-Bass.

Csikszentmihalyi, M. (1990). Flow: The psychology of optimal experience. New York: Harper \& Row.

Cummings, J. J., \& Bailenson, J. N. (2016). How immersive is enough? A meta-analysis of the effect of immersive technology on user presence. Media Psychology, 19(2), 272-309. https://doi.org/10.1080/15213269.2015.1015740

Dangxiao, W. A. N. G., Yuan, G. U. O., Shiyi, L. I. U., ZHANG, Y., Weiliang, X. U., \& Jing, X. I. A. O. (2019). Haptic display for virtual reality: progress and challenges. Virtual Reality \& Intelligent Hardware, 1(2), 136-162. https://doi.org/10.3724/SP.J.2096-5796.2019.0008

Ermi, L., \& Mäyrä, F. (2005). Fundamental components of the gameplay experience: Analysing immersion. Worlds in play: International perspectives on digital games research, 37(2), 37-53. 
Haeling, J., Winkler, C., Leenders, S., Keßelheim, D., Hildebrand, A., \& Necker, M. (2018, March). In-Car 6DoF Mixed Reality for Rear-Seat and Co-Driver Entertainment. In 2018 IEEE Conference on Virtual Reality and 3D User Interfaces (VR) (pp. 757-758). IEEE. https://doi.org/10.1109/VR.2018.8446461

Halabi, O., \& Halwani, Y. (2018). Design and implementation of haptic virtual fixtures for preoperative surgical planning. Displays, 54, 9-19. https://doi.org/10.1016/j.displa.2018.07.004

Huber, T., Paschold, M., Hansen, C., Lang, H., \& Kneist, W. (2018). Artificial Versus Video-Based Immersive Virtual Surroundings: Analysis of Performance and User's Preference. Surgical Innovation, 25(3), $280-285$. https://doi.org/10.1177/1553350618761756

Kim, K., Billinghurst, M., Bruder, G., Duh, H. B. L., \& Welch, G. F. (2018). Revisiting trends in augmented reality research: a review of the 2nd decade of ISMAR (2008-2017). IEEE transactions on visualization and computer graphics, 24(11), 2947-2962. https://doi.org/10.1109/TVCG.2018.2868591

Li, M., Ganni, S., Ponten, J., Albayrak, A., Rutkowski, A. F., \& Jakimowicz, J. (2020, March). Analysing usability and presence of a virtual reality operating room (VOR) simulator during laparoscopic surgery training. In 2020 IEEE Conference on Virtual Reality and 3D User Interfaces (VR) (pp. 566-572). IEEE. https://doi.org/10.1109/VR46266.2020.00078

McGloin, R., Farrar, K., \& Krcmar, M. (2013). Video games, immersion, and cognitive aggression: Does the controller matter? Media Psychology, 16, 65-87. https://doi.org/10.1080/15213269.2012.752428

Milgram, P., Takemura, H., Utsumi, A., \& Kishino, F. (1995). Augmented reality: A class of displays on the reality-virtuality continuum. In Telemanipulator and telepresence technologies (Vol. 2351, pp. 282-292). International Society for Optics and Photonics. https://doi.org/10.1117/12.197321

Nacke, L., \& Lindley, C. A. (2008). Flow and immersion in first-person shooters. Proceedings of the 2008 Conference on Future Play Research, Play, Share - Future Play 08. https://doi.org/10.1145/1496984.1496998

O’Brien, H. L., \& Toms, E. G. (2008). What is user engagement? A conceptual framework for defining user engagement with technology. Journal of the American society for Information Science and Technology, 59(6), 938-955. https://doi.org/10.1002/asi.20801

Paavilainen, J., Korhonen, H., Alha, K., Stenros, J., Koskinen, E., \& Mayra, F. (2017). The Pokémon GO experience: A location-based augmented reality mobile game goes mainstream. In Proceedings of the 2017 CHI conference on human factors in computing systems (pp. 2493-2498). ACM. https://doi.org/10.1145/3025453.3025871

Pan, Z., Cheok, A. D., Yang, H., Zhu, J., \& Shi, J. (2006). Virtual reality and mixed reality for virtual learning environments. Computers \& graphics, 30(1), 20-28. https://doi.org/10.1016/j.cag.2005.10.004

Pine, B. J., Pine, J., \& Gilmore, J. H. (1999). The experience economy: work is theatre \& every business a stage. Harvard Business Press.

Psotka, J. (1995). Immersive training systems: Virtual reality and education and training. Instructional Science, 23(5-6), 405-431. https://doi.org/10.1007/BF00896880

Shin, D. (2017). Empathy and embodied experience in virtual environment: To what extent can virtual reality stimulate empathy and embodied experience? Computers in Human Behavior, 78, 64-73. https://doi.org/10.1016/j.chb.2017.09.012

Slater, M. (2003). A note on presence terminology. Presence connect, 3(3), 1-5.

Slater, M., \& Wilbur, S. (1997). A framework for immersive virtual environments (FIVE): Speculations on the role of presence in virtual environments. Presence: Teleoperators \& Virtual Environments, 6(6), 603-616. https://doi.org/10.1162/pres.1997.6.6.603

Tran Duy, H. (2017). Designing a Virtual Reality Psychological Game.

Ternier, S., Klemke, R., Kalz, M., Van Ulzen, P., \& Specht, M. (2012). ARLearn: Augmented Reality Meets Augmented Virtuality. J. UCS, 18(15), 2143-2164. https://doi.org/10.3217/jucs-018-15-2143

Witmer, B. G., \& Singer, M. J. (1998). Measuring presence in virtual environments: A presence questionnaire. Presence, 7(3), 225-240. https://doi.org/10.1162/105474698565686 